\title{
Effect of Management Control System on Perceived Performance of Commercial Banks in Nepal
}

\author{
Ballav Niroula (M. Phil.) \\ ballavsir@gmail.com
}

\begin{abstract}
Management control system is to provide information that is useful for managerial decision-making, planning, monitoring and evaluation of organizational activities to alter employee behavior. The main purpose of the study is to show the effect of MCS on perceived performance of Nepalese commercial Banks. This study followed the descriptive and inferential statistics. Descriptive and analytical research design has been used. As per the descriptive statistics most of the respondent were agreed that MCS has increased the perceived performance of commercial Banks. There exists strong correlation among the dependent and independent variables. The correlation is statistically significant at 1 percent level of significant.
\end{abstract}

Keywords: Perceived performance, Budgeting, Control environment, Risk assessment, Monitoring and supervision, Information and communication.

\section{Background}

In recent years, many organizations have experienced numerous changes in their organizational structures and business processes as a result of the changing business environment. This paper develops a conceptual framework that produces past research on management control. The classification and level of management control can be considered to be a subsequent of firm flexibility and governor capacity. Management is the "the process of using organization resources to achieve organizational objectives through the functions of planning, organizing and staffing, leading, and controlling" (DuBrin 2000). Control is considered a very important function of managers. Control is defined as "keeping things on track".

Federal regulation makes permitted hostile takeovers within commercial banking more expensive and time consuming than in non-banking sectors. Interstate banking regulations prohibit many bank mergers. In addition, bank takeovers typically face extensive delays. This may lower the frequency of hostile takeovers that depend on the ability to close the transaction quickly. Bank takeovers require prior approval from federal bank regulators and state authorities. Federal regulation and moral hazard clearly play a role in shaping the corporate control mechanism that operates in banks, and may make it much different from that in other firms. Nevertheless, a relatively small amount of literature, particularly recently, attempts to document empirically the existence of corporate control problems in banks.

Akroyd \& Maguire, (2011). Performance can be defined as the results of the activities of an organization or investment over a given period of time. Based on literature review, the results of MCS on organization performance are hard to predict. A positive relationship between performance and the implementation of MCS will be expected if MCS provide significant information for coordination and learning, and there is some indication about this matter in the performance field. 
DuBrin, (2000). It is possible to accept the designation and extent of management control as a consequence of firm versatility and governing ability. Management is the practice of utilizing organizational resources through the functions of preparing, coordinating and staffing, guiding and managing, to achieve organizational goals.

Basically, the aim of MCS is to provide information that is useful for the decision-making, preparation, tracking and assessment of corporate practices by management to improve employee behavior. (Merchant \& Otley, 2007).

Krause, (2005), studied on the performance management system is a continuous decision mechanism of an enterprise with a fully integrated system to optimize business processes, methodologies, software tools, measurements, and structure that guide the performance of an entity.

COSO (1992), studied on internal control process can be categorized as follows: compliance with applicable laws and regulations; reliability of financial reporting; and effectiveness and efficiency of operations. According to COSO framework, it is proposed that internal controls are to be performed based upon five principles components related to ensuring regularity, efficiency, operational effectiveness, and reliable financial reporting which must be integrated into business processes across the entire entity, in its efforts to achieve objectives.

Tsamenyi et al. (2011) investigated the linkages between these three key variables in management accounting, but with three important exceptions as they relate to this current study. First, Tsamenyi et al.'s study was not designed to examine the linkages between these three variables in minority-owned businesses. Instead, Tsamenyiet al. gathered data from a population of respondents "chosen from the yellow pages of the telephone directory of Urumuchi in Xinjiang, China" (p. 197). This source of data clearly indicates that the Tsamenyi et al.'s study was not by design positioned in minority-owned businesses. Second, Tsamenyi et al. conducted their research in China. To the degree that China and the United States differ in their business environments, one would expect different outcomes from the same study conducted in two different countries. Third, in contrast to the research of Tsamenyi et al. the current study targeted specifically manufacturing business organizations designated as minority-owned.

Control is also discussed in the literature as part of the strategic implementation process. Control, as the word applies to a function of management, involves influencing human behavior, because it is people who make things happen in an organization. In other words, control involves managers taking steps to help ensure that human beings do what is best for the organization.

Olatunji (2009) analyzed on the effect of an internal control system in the banking sector, and according to the findings, Poor effective internal control system is the major cause of fraud in the banking sector. While, other researcher revealed that ineffective internal control system often causes a decrease in the performance of the bank due to inability to prevent and detect fraudulent activities in the system.

Tsamenyi et al. (2011) conducted survey-based quantitative research to investigate the hypothesized contingent relationship between business strategy, management control system and performance in a sample of 215 enterprises operating in the Xinjiang autonomous region of China. They found that those organizations classified as pursuing differentiation strategy used more nonfinancial-based management control system, and this positively impacted organizational performance conversely, the study found that organizations classified as pursuing low cost strategy used more financial-based management control system, and this had a positive relationship on organizational performance.

MCS can motivate the managers themselves.i. e. at the beginning of each year, managers can negotiate their objectives and the resources necessary for their achievement with their superiors. At the end of the year, the performance of every manager can then be compared with the results they attained.

\section{Research issues}

What is the present management control practices in Nepalese organization?

Are the management control system and perceived performance inter related? 


\section{Objectives of The Study}

The main objectives of this project work is to show the relationship between management control systems applied by organization and perceived performance of selected organizations. Other objectives are as follows:

To analyze the present practices of management control in selected organizations.

To examine the association between management control systems and perceived performances. Independent Variables

Dependent Variable

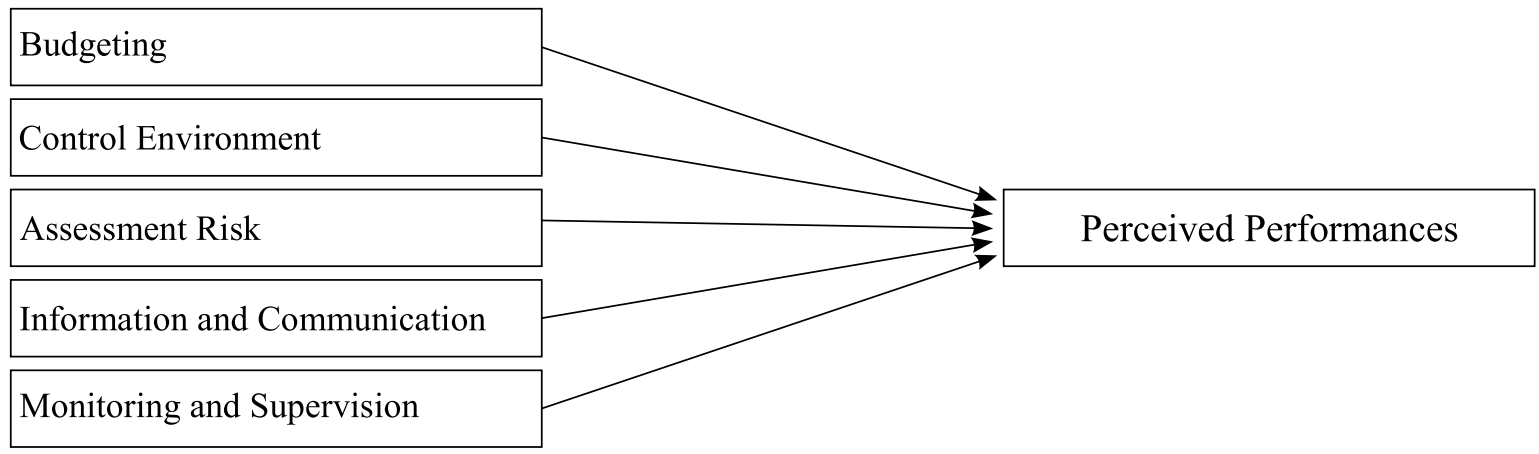

Figure 1. Theoretical Framework

The findings of this study had implications with respect to theory building in MCS in particular and the management accounting discipline in general. Because the outcome of this research supported and extended previous research. The outcome of this research held practical business practice implications for managers and policy-makers. This study will useful for the future researcher for the determination of relationship between MCS and perceived performance. This is also helpful to the organizations to analyze the measure the performance of the organization and to make the effective decision making. Academician can also have benefited by this studies. The business and service organization can apply the management control system following the decision of this studies. This is useful for social changes on the basis of result obtained from this study. One of the key contributions of this study was its significance to practice to the Nepalese economy in general and Banking organizations in particular.

\section{Research Methodology}

This study is mainly focused on descriptive and casual research design.Five point Likert scale has been used to measure the variables. Descriptive and inferential statistics is used to analyze and interpret the result. Questionnaire is divided into six part on the basis of independent variables and each group includes 4 questions.Data were collected through open ended questionnaire from middle level and lower level employees of selected banks. There are total 28 commercial banks in Nepal. Out of which only three commercial Banks are selected as a sample for this study. Total population of the respondents were 670 in three commercial banks(sources) and Questionnaire were distributed to total 200 respondents of three banks and 171respondents were response on time and returned. Three level employees' officer, manager and executive were selected as respondents.In order to obtain the required data for the study, questionnaire has prepared for the respondents. Before distributing the questionnaires, prior approach has made to the respondents and their approval has got by convincing the purpose of the difficulties has felt by the respondents to some quarries has overcome by clarifying the sense of the questions. The questionnaire was created using five-point Liker scale $5=$ Always agree, $4=$ usually agree, $3=$ Sometimes agree, 2 =rarely agree and $1=$ disagree

\section{Hypothesis}

This study tried to test the following hypothesis:

$\mathbf{H}_{1}$ : There is positive relationship exists between Budgeting and perceived performance. 
$\mathbf{H}_{2}$ : There is positive relationship exists between Control environment and perceived performance.

$\mathbf{H}_{3}$ : There is positive relationship exists between Risk assessment and perceived performance.

$\mathbf{H}_{4}$ : There is positive relationship exists between information and communication and perceived performance

$\mathbf{H}_{5}$ : There is positive relationship exists between monitoring and supervision and perceived performance

$\mathbf{H}_{6}$ : There is positive relationship between management control system and perceived performance.

\section{Test of Reliability}

Cornbach's alpha helps to test the reliability of the variables. The theory explains that there should be at least 0.5 or above the aggregate Cornbach's Alpha shows the variables are reliable. Aggregate Cornbach's Alpha of the study of six variables is 0.944 and all other Cornbach;s Alpha of individual variables if item deleted are less than 0.944 which shows the test reliability is reliable. it shows all six variables are retained for the study.

\section{Discussion and Result}

Descriptive statistics

Table 1

Effects of Budgeting on Perceived Performance

Test Scale - 3

\begin{tabular}{lccc}
\hline Statements & Mean & S.D. & Rank \\
\hline Have your organization prepared the budget? & 4.62 & 0.73 & 1 \\
In your organization prepared budget is implemented properly. & 4.13 & 0.87 & 2 \\
In your organization specific outcomes are measured, monitoring and & 4.11 & 0.79 & 3 \\
control against budget. & & & \\
Actual result of the organization is compared with budget for evaluation. & 4.06 & 0.91 & 4 \\
You are aware of management control system. & 3.78 & 1.29 & 5 \\
\hline
\end{tabular}

Source: Research survey, 2020.

Table 1 exhibits the mean and standard deviation of the Budgeting factors selected for the study. All the budgeting factors are favored and agreed by the Nepalese respondent. This is supported by the weighted average mean score tabulated. Among the selected factors "Have your organization prepared the budget?" and in your organization Prepared budget is implemented properly. Were found first and second preference. However, MCS awareness in the organization is found least to be known.

Table 2

Effects of Control Environment on Perceived Performance

Test Scale - 3

\begin{tabular}{lccc}
\hline Statements & Mean & S.D. & Rank \\
\hline There are rules and regulations in your organization & 4.48 & 0.86 & 1 \\
Rules and regulations are followed properly & 4 & 0.93 & 3 \\
Organizational structure is clearly defined. & 4.25 & 0.88 & 2 \\
Timely and effective decision making & 3.75 & 0.9 & 5 \\
The effectiveness of internal control is monitored in the normal course of & 3.94 & 0.93 & 4 \\
the business. & 3.75 & 0.8 & 5 \\
There is proper delegation of responsibility and authority. & & & \\
\hline
\end{tabular}

Source: Research survey, 2020. 
Table 2 explains the mean and standard deviation of control environment. All the mean values of control environment are greater than the test scales of 3 which explain the variables are positively and highly effective in the commercial Banking sectors of the Nepal. It is supported by the result of the officer, manager and executive level respondent selected for this study. Result of this descriptive statistics explains that the first and third control environment variables are highly effected on perceived performance. On further research option four and six are least applicable in the commercial banks of Nepal.

Table 3.

Effects of Risk Assessment on the Perceived Performance

\begin{tabular}{lccc}
\hline Statements & Mean & S.D. & Rank \\
\hline Periodic evaluation and reporting system is timely done & 4.19 & 0.82 & 1 \\
Management control system has properly defined authority and & 3.89 & 0.74 & 5 \\
responsibility to prepare and evaluate the report & 4.16 & 0.77 & 2 \\
Management has defined appropriate objectives of organization. & 4.14 & 0.78 & 3 \\
Management identifies risk that affect achievement of objectives. & 4.05 & 0.96 & 4 \\
Training and seminar are performed regularly. & & &
\end{tabular}

Source: Research survey, 2020.

Mean and standard deviation posits in table 3 shows that all risk assessment variables are positively effective because mean values of all five variables are greater than the test scale value. The first and third risk assessment variables are high effects with their highest average values. But the second variable is comparatively lesser compare to other variables.

Table 4.

Effects of Information and Communication on Perceived Performance.

Test Scale -3

\begin{tabular}{|c|c|c|c|}
\hline Statements & Mean & S.D. & Rank \\
\hline Adequate information is required to implement MCS & 4.13 & 0.87 & 2 \\
\hline $\begin{array}{l}\text { In your organization MCS assist in decision making communicate the } \\
\text { objectives }\end{array}$ & 3.9 & 0.89 & 3 \\
\hline Result are communicated to concerned department in time & 3.79 & 0.99 & 5 \\
\hline $\begin{array}{l}\text { Management ensures that reliable and relevant information is } \\
\text { communicated at all level. }\end{array}$ & 3.87 & 0.92 & 4 \\
\hline $\begin{array}{l}\text { Communication helps to evaluate how well guidelines and policies are } \\
\text { working and being implemented. }\end{array}$ & 4.24 & 0.89 & 1 \\
\hline
\end{tabular}

Source: Research survey, 2020.

Table 4 represents the descriptive statistics of five variables of information and communication. On the basis of test scale 3 of these five variables all the mean values are greater.It explains that management control system is affected by these variables on the basis of respondent's view. Among these variables fifth and first variables are high important with their mean values of 4.24 and 4.13 respectively and other variables are moderately effective. But "result is communicated to concerned department on time" was found least concerned to the employees with minimum mean value of 3.79 and SD of 0.99 . 
Effects of Monitoring and Supervision on Perceived Performance.

\begin{tabular}{lccc}
\hline Statements & Mean & S.D. & Rank \\
\hline Periodic evaluation and reporting system is timely done & 4.05 & 0.771 & 1 \\
Compare outcomes with expectation regularly. & 3.86 & 0.84 & 5 \\
In your organization continuous and constant monitoring system has been & 3.87 & 0.793 & 4 \\
adopted & & & \\
\hline In your organization the executive track a progress towards goal. & 3.95 & 0.941 & 3 \\
Line of authority is clear and specified. & 3.98 & 0.924 & 2 \\
\hline
\end{tabular}

Source: Research survey, 2020.

Table 5 represent of respondents views on monitoring and supervision. It is found that monitoring and supervision was taken in to consideration. Thus the test result of all variable related to supervision and monitoring are higher than the test scale. Among them "Periodic evaluation and reporting system is timely done" was found highest with average 4.05 and SD 0.771. It shows the commercial banks do not compare their outcomes with their expectation regularly.

Table 6

Descriptive Statistics of Perceived Performance

Test Scale- 3

\begin{tabular}{lccc}
\hline Statements & Mean & S.D. & Rank \\
\hline $\begin{array}{l}\text { Implementation of MCS has helped to improve profit in your } \\
\text { organization. }\end{array}$ & 4.13 & 0.871 & 1 \\
$\begin{array}{l}\text { Implementation of MCS has helped to improve productivity in your } \\
\begin{array}{l}\text { organization. } \\
\text { Implementation of MCS has helped to improve capacity utilization in }\end{array}\end{array}$ & 4.03 & 0.95 & 3 \\
$\begin{array}{l}\text { your organization. } \\
\text { Queries of the stakeholders and employees are timely response. }\end{array}$ & 4.11 & 0.797 & 5 \\
MCS is used to evaluate performance that increase market share & 3.97 & 0.761 & 2 \\
\hline
\end{tabular}

Source: Research survey, 2020.

Table 6 exhibit the result of perceived performance of selected commercial banks. "Implementation of MCS has helped to improve profit in your organization." Shows high impact with test result of 4.13 mean value and $0.871 \mathrm{SD}$. But the variable "Implementation of MCS has helped to improve capacity utilization in your organization "have least effect on perceived performance with mean 3.90 and SD 0.797.

Table 7

Pearson Correlation Coefficient of the Variables.

\begin{tabular}{lcccccc}
\hline & PerPer & Bud & ConEv & RisAss & InfCom & MonSup \\
\hline PerPer & 1 & & & & & \\
Bud & $.633^{* *}$ & 1 & & & & \\
ConEv & $.656^{* *}$ & $.779^{* *}$ & 1 & & & \\
RisAss & $.670^{* *}$ & $.706^{* *}$ & $.808^{* *}$ & 1 & & \\
InfCom & $.832^{* *}$ & $.713^{* *}$ & $.737^{* *}$ & $.714^{* *}$ & 1 & \\
MonSup & $.688^{* *}$ & $.680^{* *}$ & $.742^{* *}$ & $.694^{* *}$ & $.701^{* *}$ & 1 \\
\hline
\end{tabular}

Note: $* *$ Correlation is significant at the 0.01 level (2-tailed). 
Table 7 represents the correlation between budgeting and perceived performance 0.633 which is the moderate relation between the variables. There is a highest relation between the two variables risk assessment and control environment 0.808 . Correlation of all variables is above than 0.6 which shows there is strong relation exist in the variables.

\section{a. Dependent Variable: Perceived Performance}

The results are based on Primary data of 3 commercial banks by using linear regression model. The model is:

$\mathrm{PP}=\beta_{0+\beta 1 \text { Bud }}+\beta_{2}$ ContEnv $+\beta_{3}$ RisAss $+\beta_{4}$ InfoComm. $+\beta_{5}$ MonSup. $+\mathrm{e}^{\mathrm{t}}$

Where, $\quad \mathrm{PP}=$ Perceived Performance

Bud. $=$ Budgeting

ContEnv $=$ Control Environment

RiskAss $=$ Risk Assessment

InfoComm=Information and Communication

MonSup $=$ Monitoring and Supervision

\section{Findings and Conclusion}

The average mean and S.D. of budgeting 4.137 and 0.671 shows that budgeting highly effect on perceived performance of Nepalese commercial banks. It is proved that preparation and implementation of budget is an important tool for increase the perceived performance. Control environment plays a vital role in the enhancement of the perceived performance in any organization. High mean 4.026, low standard deviation 0.6441 and high correlation 0.678 between control environment and perceived performance shows it helps to increase performance of the commercial banks. Hypothesis one "There is positive relationship exists between Budgeting and perceived performance." Shows negative relationship therefore hypothesis one is not accepted. Result of this study is contrary with Gooneratne and Hoque (2013).Hypothesis two "There is positive relationship exists between Control environment and perceived performance" shows negative relationship so hypothesis two is rejected. The result of risk assessment and perceived performance is positive so, the hypothesis three is accepted. This result is supported by the result of Olatunji (2009). There is positive relation exist between the all hypotheses therefore all hypothesis is fail to reject. The study demonstrated highest positive correlation in between information and communication and perceived performance (0.832) at one percent level of significance. However, the lowest correlation records between budgeting and perceived performance at (0.633) also at 1 percent level of significance.

\section{Conclusion}

The major objective of the study is to observe the present practices of management control systems and perceived performance in selected organizations. This study used budgeting, control environment, risk assessment, information and communication and monitoring and supervisions independent variable and perceived performance as dependent variable. Budgeting and control environment have negative effect on perceived performance where as other independent variables have positive effects.

On the basis of above analysis, the study it was found that management control system is varying according to different conditions. MCS is effected by different variables like budgeting. Control environment, risk assessment, monitoring and supervision and information and communication. MCS has also effected by legal environment, culture of organization financial elements and other factors. Here in this study information and communication is very important factors for the perceived performance of selected commercial banks according to views of the respondents.

The use and design of MCS are attractive topic and of high significance for top management in managing and directing the behavior of their assistant. 
This study focused on budgeting, control environment, risk assessment, monitoring and supervision and information and communication as a tools of management control system to measure the perceived performance of commercial banking sector of Nepal. The researcher can use these component to measure the financial as well as perceived performance of other manufacturing and service organization. In the coming future further research can be performed to analyze the performance and market responsiveness, Innovativeness, Market orientation, Organizational learning using the same independent variables.

\section{References}

Abdul-Karim, Z., Azman-Saini, W.N.W. \& Abdul-Karim, B. (2011). Bank lending channel of monetary policy: Dynamic panel data study of Malaysia. Journal of Asia-Pacific Business, 12(3), 225-243.

Aisen, A. \& Franken, M. (2010). Bank Credit during the 2008 Financial Crisis: A Cross-Country Comparison. IMF Working Paper WP/10/47.

Akroyd\& Maguire, Bisbe \& Otley (2000)the Use of Control Systems in New Product Development Innovation: Advancing the 'Help or Hinder' Debate

Andrew J. Du Brin (2000) essentials of Management South-Western College Pub. 2000 Journal of Business \& Economics, pp $65-81$

Barney, J.B. and Clark, D.N. (2007) Resource-Based Theory Creating and Sustaining Competitive Advantages. Oxford University Press, Oxford pp 327

Bisbe and Otley (2004) the effects of the interactive use of management control systems on product innovation, Journal of Economic History, 66 (2), 417-432.

Chenhall (2003) management control systems design within its organizational context. Accounting, Organizations and Society, 28(2-3), Pp 127-168

COSO. (1992) internal Control - Integrated Framework (executive summary). Jersey City. Retrieved from www.coso.org/documents/Internal Control-Integrated Framework.

Danneel C. (2002) the dynamics of product innovation and firm competence 19 September 2002 ISBN 0-273-01914-7

Henri C. (2006) organizational culture and performance measurement systems Working paper, 1 (1374).

Jamil, C. Z. M., \& Mohamed, R. (2013) the Effect of Management Control System on Performance Measurement System at Small Medium Hotel in Malaysia. International Journal of Trade, Economics and Finance, 4(4), 202.

Kald, Nilsson, \& Rapp, (2000) strategy and Management Control: The Importance of Classifying the Strategy of the Business British Journal of Management 11(3):197-212 - September 2000

Kapiyangoda, K., \&Gooneratne, T. N. (2013, 2014). Change of management control from the balanced scorecard to budgeting: case study evidence from a commercial bank. Colombo Business Journal, $4(2) \& 5(1)$.

Kenneth A. Merchant (1985 control in Business Organization. Boston, Pitman, 161 pp., ISBN 0-27301914-7

Macintosh, N. B., \& Daft, R. L.(1987). Management control systems and departmental interdependencies: an empirical study. Accounting, Organizations and Society, 12(1), 49-61.

Merchant, K. A., \&Otley, D. T. (2007). A review of the literature on control and accountability. Handbook of Management Account Research. (Ed.) Chapman, CS, Hopwood, AG, Shields, MD, 785-804.

Mawanza, W. (2014). An analysisof the main forces of workplacefraud in Zimbabweanorganizations:The fraud triangle perspective. International Journal of Management Sciences and Business Research, (2), 86-94.

Olatunji OC (2009) Impact of Internal Control System in Banking Sector in Nigeria. Pakistan Journal of Social Sciences, 2009

Robert Simon's (1995) How Managers Use Innovative Control Systems to Drive Strategic Renewal217 pages, Harvard Business School Press, 1995 
Robert N. Anthony (1965) Planning and Control Systems: A Framework for Analysis Hardcover - January 1,1965

Salas, V. \&Saurina. J. (2002). Credit Risk in Two Institutional Regimes: Spanish Commercial and Savings Banks. Journal of Financial Services Research, 22(3), 203-224.

Tsamenyi, Sahadev, \&Qiao, (2011) management Control System Business Strategy, and Firm's Performance

Tsamenyi et al. (2011) Te relationship between business strategy, management control systems and performance: Evidence from China. Advances in Accounting 27(1):193-203 · June 2011

Tsamenyi et al. (2011) the relationship between business strategy, management control systems and performance: Evidence from China Advances in Accounting 27(1):193-203 · June 2011

Vukadinovic, P. (2015) management control in modern organizations - January 2015. The Credit Administrator, 2(2), 32-39.

While, Akroyd and Maguire (2011) the roles of management control in a product development setting. Qualitative Research in Accounting \& Management (September):212-237 . 
Issue 1 May/June 2020 - 